\title{
Climate Study of Owerri and Comparative Analysis of Different Methods of Base Factor Computation
}

\author{
Stanley I. Echebima*, Benjamin C. Ndukwu, Andrew A. Obafemi \\ Institute of Natural Resources, Environment and Sustainable Development, University of Port Harcourt, Port Harcourt, Nigeria \\ Email: ^sechebima@yahoo.com, ^staneche@gmail.com, Benjamin.ndukwu@uniport.edu.ng, Andrew.obafemi@uniport.edu.ng
}

How to cite this paper: Echebima, S.I., Ndukwu, B.C. and Obafemi, A.A. (2019) Climate Study of Owerri and Comparative Analysis of Different Methods of Base Factor Computation. Atmospheric and Climate Sciences, 9, 310-322.

https://doi.org/10.4236/acs.2019.93022

Received: May 2, 2019

Accepted: June 15, 2019

Published: June 18, 2019

Copyright ( 2019 by author(s) and Scientific Research Publishing Inc. This work is licensed under the Creative Commons Attribution International License (CC BY 4.0).

http://creativecommons.org/licenses/by/4.0/

\begin{abstract}
This study analyzed three decades of the temperature and rainfall data of Owerri, South Eastern Nigeria and in the process carried out a comparative analysis of using three different methods namely the mean, median and jackknife to derive the base data upon which the anomalies are computed with a view to ascertaining if any significant differences exist in the obtained results. And for rainfall which is seasonal, a further z-score method was employed to remove the effect of seasonality by dividing the anomalies with its standard deviation. Linear regression analysis was used to interpret the anomaly plots and the trend in climate from 1986 to 2015 in Owerri extracted. For the temperature analysis, the mean and median methods gave similar result which makes the mean method an acceptable method due to its simplicity, taking cognizance of the heavy computation in the other methods. Interestingly, for the rainfall analysis, the mean and jackknife methods gave the same result which also makes the mean method acceptable to avoid the heavy computations of the other two. ANOVA on the anomalies so derived showed no significant difference in their mean, thus underpinning the choice of the mean method. Using the outcome of the mean method therefore, the analyzed mean minimum temperature and mean maximum temperature indicate that the night time temperature has increased in Owerri within the period under consideration by $0.0186^{\circ} \mathrm{C}$ each year and the daytime temperature increased by $0.01^{\circ} \mathrm{C}$ per year respectively, thus indicating that a warming climate change has taken place in Owerri. Within the same period, the rate for rainfall on the other hand showed a decrease. In summary, the simple mean method of base computation suffices over the median and jackknife methods in climate studies for Owerri, a trend of warming climate has taken place in Owerri with increases in both daytime and night temperatures but with a reverse trend in rainfall which will require further inquiry.
\end{abstract}




\section{Keywords}

ANOVA, Jackknife, Median, Mean

\section{Introduction}

The climate of an area is discerned using the weather data of the area recorded over the years. According to the World Meteorological Organization (WMO) [1], the length of the years required is dependent on the weather element under consideration stating that temperature requires more than 30 years and rainfall requires less than 30 years, thus making thirty years a compromise for the sake of consistency. This notion of 30 years has been accepted by many climate scientists and Kelly and Fret well affirmed that thirty years' study of the weather elements is sufficient to indicate a climate change [2]. This notion informed the choice of three decades of climate data of Owerri spanning the years from 1986 to 2015 used to carry out this study.

These weather records are an accumulation of data collections of the weather elements done each day and mostly stored as daily, monthly or yearly averages for the weather elements under consideration over the years. Therefore it is time variant which we denote as $R(t)$ or $R_{t}$ where $t$ is the time say year $1,2,3, \cdots, 30$. It is from this raw data that the "climate average", $\bar{A}$ (also called base factor, climatology or base data) is computed.

Thus, it has embedded in each year the effect of the seasons like rainy season, dry season and Harmattan season for those in the tropics or seasons like winter, spring, summer and autumn for the others. Over the years too, improvements in technology necessitate changes in software and equipment which in one way or the other has an effect on the raw data. Another way the raw data could be affected is the relocation of the measuring weather station or the spread of the data recordings and even changes in personnel. Regardless of the situation however, measurement is not an "exact science" and the data provided by the Nigerian Meteorological Agency (NIMET) was used in the study.

The task is to remove the effect of seasonality or other external effects from the raw data, $R(t)$ which gives an indication of the trend in climate. One way of doing this is to compute the base factor or climatology, $\bar{A}$, which is the mean of the monthly or yearly data and subtract it from the raw (monthly or yearly) data. The resultant data is the anomaly time series $A(t)$ given as:

$$
A(t)=R(t)-\bar{A} \text {, where } t=1,2,3, \cdots, 30
$$

The computation of the base factor (or climatology) is vital in the analysis of climate of the area and the Mean, Medan, Jackknife and Z-score methods of computation have been dealt with in great detail by Jaya Kawale and coauthors [3].

Another method is using the Composites method. According to the International Research Institute (IRI), Composites are the average of variables taken 
over a specially selected time period with a common characteristic [4]. For instance, when a weather station is relocated, you can batch the data from each location together to form a composite data.

The Mean, Median, Jackknife and Z-score methods were used to analyze the weather data recorded at the Owerri Meteorological synoptic station over the thirty years period spanning 1986 to 2015 .

Owerri meteorological synoptic station is located between Lat. $05^{\circ} 29^{\prime} \mathrm{N}$ and Long. $07^{\circ} 02^{\prime} \mathrm{E}$, within the study area Owerri metropolis in Imo State, South Eastern part of Nigeria which is urban in nature. Presently it has been decommissioned and is relocated within the premises of the Imo State Airport about 20 $\mathrm{km}$ away between Lat. $05.48^{\circ} \mathrm{N}$ and Long. $07.03^{\circ} \mathrm{E}$ which is a rural area. The year of relocation is not officially known to the authors, so the composite method could not be added in this analysis but will be another subject of study when it is known. The study area is part of Southern Nigeria which is characterized by a tropical wet climate or monsoon climate according to the Koppen-Geiger climate classification [5] shown in the map in Figure 1 below. It has the wet season when rains fall for about six months between April-September with a break in August, a dry season from October to March with a drier dusty Harmattan from December to February.

The mean minimum temperature is the coldest surface air temperature recorded at night while mean maximum temperature is the warmest surface air temperature of the day, both measured in degree Celsius or centigrade $\left({ }^{\circ} \mathrm{C}\right)$ with a mercury (minimum-maximum) thermometer.

The rain gauge collects the rain when it falls and thereafter measured with a cylinder graduated in millimeter $(\mathrm{mm})$.

Recent climatic studies at a regional scale have indicated an increasing trend in the rainfall, night and daytime temperatures of southern Nigeria, but with fluctuations [6].

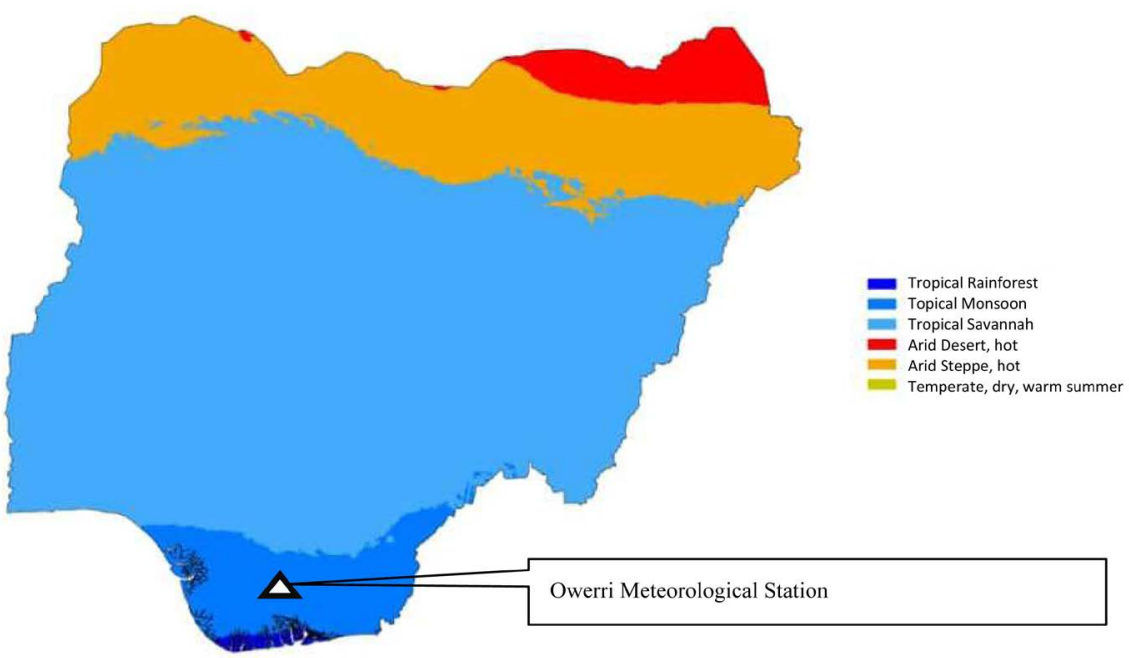

Figure 1. Koppen-Geiger climate classification map for Nigeria. Source: Beck, H. E., et al. (2018). 
At the local level, Ukaegbu et al., analyzed Land Surface Temperature (LST) for Owerri metropolis over the period 1986 to 2016, and concluded that LST has increased in Owerri for both the lowest and highest temperatures [7], connoting increases in night time and day time temperatures respectively. Alexander Selemo and co-authors in their study of Owerri for the ten year period from 1998 to 2007, observed that the average annual temperature showed an increasing trend from 2001 [8]. All these point to warming climate change situation in Owerri. On evapotranspiration, the study further found a fairly constant variation in evaporation from 2002 indicating deforestation ([8], ibid), which in our opinion could result in less amount of rainfall.

\section{Methodology}

The meteorological data for the analysis was sourced from the Nigerian Meteorological Agency, NIMET for the years 1986 to 2015 and it provided the monthly data for the mean minimum temperature, mean maximum temperature and rainfall data, which were then averaged to get the yearly data accordingly.

From the 30-year data for each weather element, the climate averages or base factor were computed using the simple mean, median and jackknife methods. The jackknife method is a Quenouille Tukey jackknife approach [9] elaborated in the paper by $\mathrm{Wu}$.

In the Mean Method, the base factor was derived by computing the average of the values of the raw data under consideration. The anomaly is then computed by subtracting the mean from the raw data.

In the Median Method, the base factor is simply the median value. The data is first arranged either in ascending or descending order and the middle value (or average of the two middle values in case of even dataset) becomes the base factor. The anomaly is then computed by subtracting the median value from the raw data.

In the Jackknife Method, the base factor is calculated by taking the average of the data records except the year under consideration. A lot of computation is involved in this approach. The anomaly is then computed by subtracting the base factor from the raw data.

Z-score Method: This is also called the standardized anomaly and is calculated by dividing the anomaly derived by any of the three methods stated above by the standard deviation of the anomaly time series. The steps to compute the standard deviation is available in any standard book of Statistics, but is briefly summarized here. The first step is to square each value in the anomaly time series and find the mean of those squared values. Then calculate the square root of that, which is the standard deviation-a measure of the distance between the raw data and its mean. It has no units. The standardized anomalies calculated this way has the property of mean value of zero and standard deviation of one. This method removes the influence of season and effects of location move or spread and best suited to analyze rainfall data because rainfall is a seasonal event. 
Composites: In this approach data of peculiar or similar characteristics are batched together in piecewise fashion. For instance, the 30 years climate data can be batched in half decades or even in decades as the case may be if it is established for instance that there is a location move in the weather station within the thirty years period.

In order to ascertain the climate of Owerri, the anomalies are plotted in columns for the mean minimum temperature, mean maximum temperature and rainfall. Thereafter linear regression method was used to fit a line of best-fit and derive the trend for each weather anomaly. The results for the different methods of analysis were then compared for any peculiarities in the outcome.

To execute a comparative analysis of the different methods of computing the base factor, a statistical one way analysis of variance (ANOVA) was carried out on the anomaly time series to ascertain if any significance differences existed in their means. And by extension any differences in the obtained results for the Owerri climate study.

\section{Results and Discussion}

The results show that regardless of the method used to derive the anomalies, the day time and night time temperatures are generally increasing for Owerri metropolis while rainfall shows a decline. However, with a 95\% confidence using one way ANOVA the results indicates that for areas like Owerri metropolis, the Simple Mean method suffices over the Median and Jackknife methods in the computation of the base factor used in the derivation of anomalies used in climate study. The details of these results are shown in the paragraphs below.

\subsection{Mean Minimum (Night Time) Temperature}

The results using the simple mean, median and Jackknife methods to derive the base data used for the anomaly computations and the subsequent anomaly plots are shown in Figures 2-4 below for the mean minimum (night time) temperature.

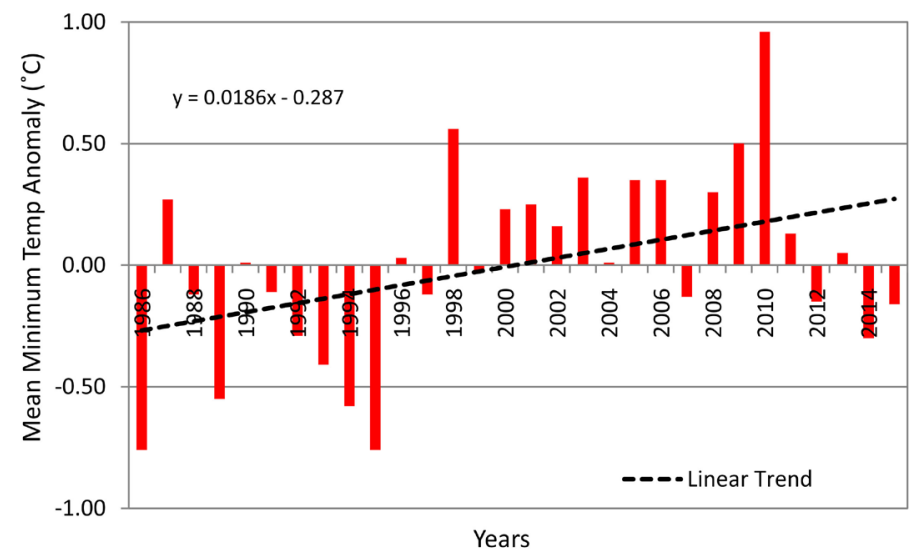

Figure 2. Mean minimum temperature anomaly for Owerri using the simple mean method to compute the base data. Source: Stanley I Echebima, Benjamin C. Ndukwu \& Andrew A. Obafemi. 


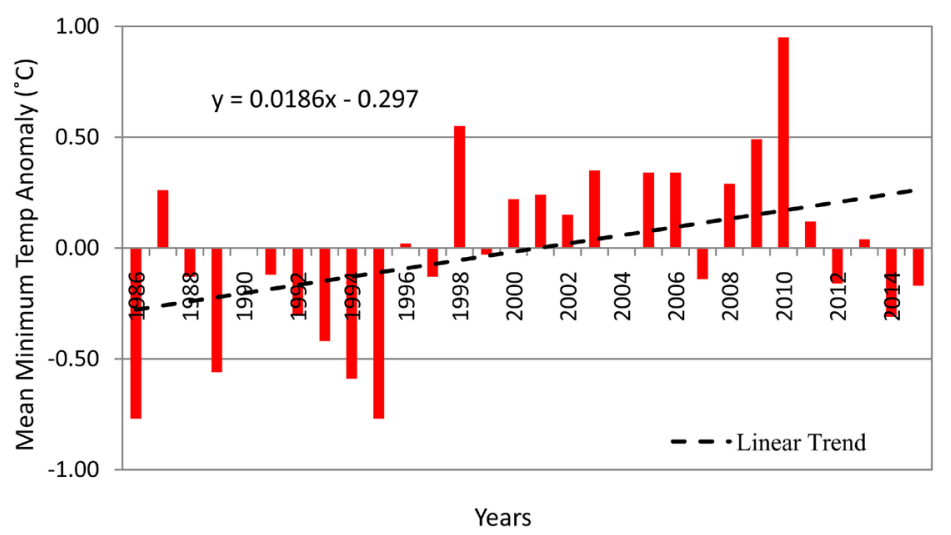

Figure 3. Mean minimum temperature anomaly for Owerri using the median method to compute the base data. Source: Stanley I Echebima, Benjamin C. Ndukwu \& Andrew A. Obafemi.

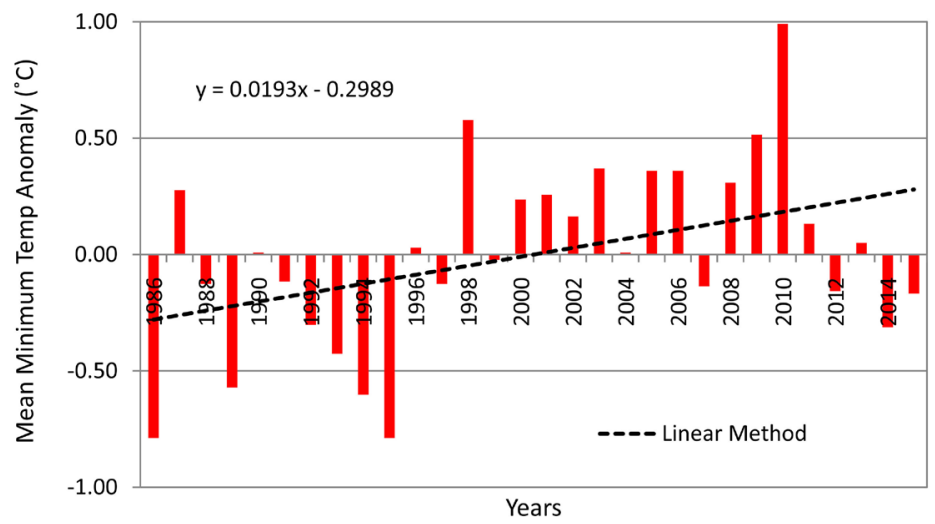

Figure 4. Mean minimum temperature anomaly for Owerri using jackknife method to compute the base data. Source: Stanley I Echebima, Benjamin C. Ndukwu \& Andrew A. Obafemi.

The climate trends in the above graphs are summarized and compared in Table 1 below for the mean minimum (night time) temperature.

\subsection{Mean Maximum (Day Time) Temperature}

The same methods of analysis done above were extended for the trend analysis for the maximum (day time) temperature for the Owerri and the results are shown in Figures 5-7 below.

A comparison of the trend in Owerri climate with regard to the day time temperature is shown in Table 2 below.

\section{Analysis of Variance (ANOVA)}

The anomaly time series from which the above plots were made are shown below in Table 3(a) and Table 3(b) below.

Statistically there is one dependent variable which is the anomaly computation and three independent variables which are the methods (simple mean, median and jackknife) used in computing it. Our null hypothesis $\left(\mathrm{H}_{\mathrm{o}}\right)$ is that for areas 


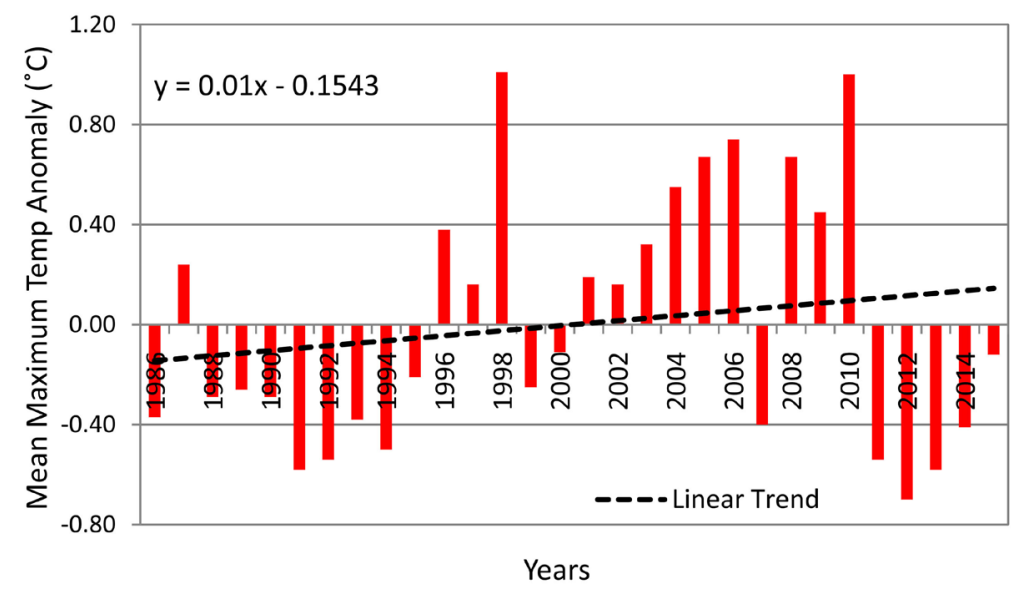

Figure 5. Mean maximum temperature anomaly for Owerri using the simple mean method to compute the base data. Source: Stanley I Echebima, Benjamin C. Ndukwu \& Andrew A. Obafemi.

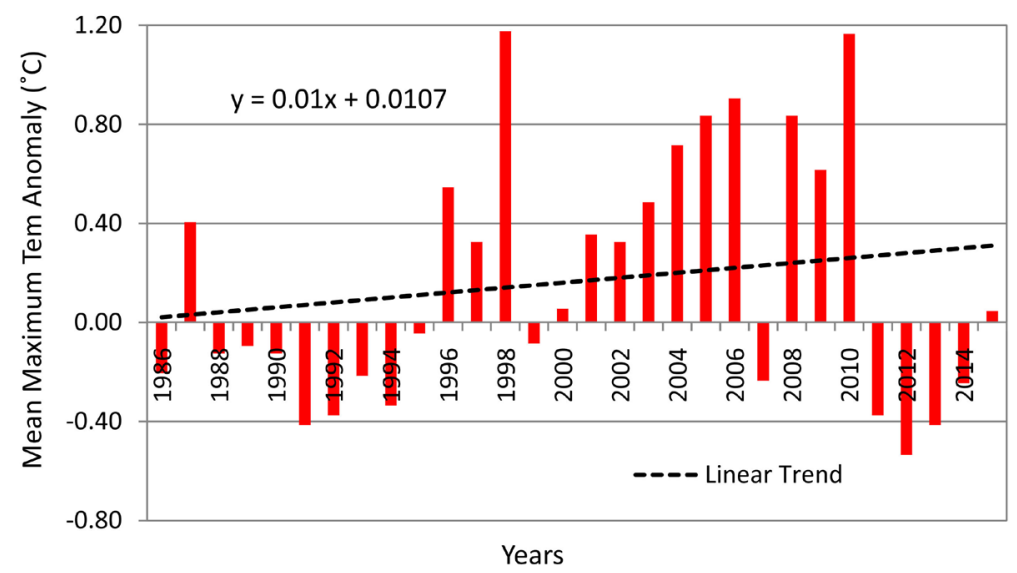

Figure 6. Mean maximum temperature anomaly for Owerri using median method to compute the base data. Source: Stanley I Echebima, Benjamin C. Ndukwu \& Andrew A. Obafemi.

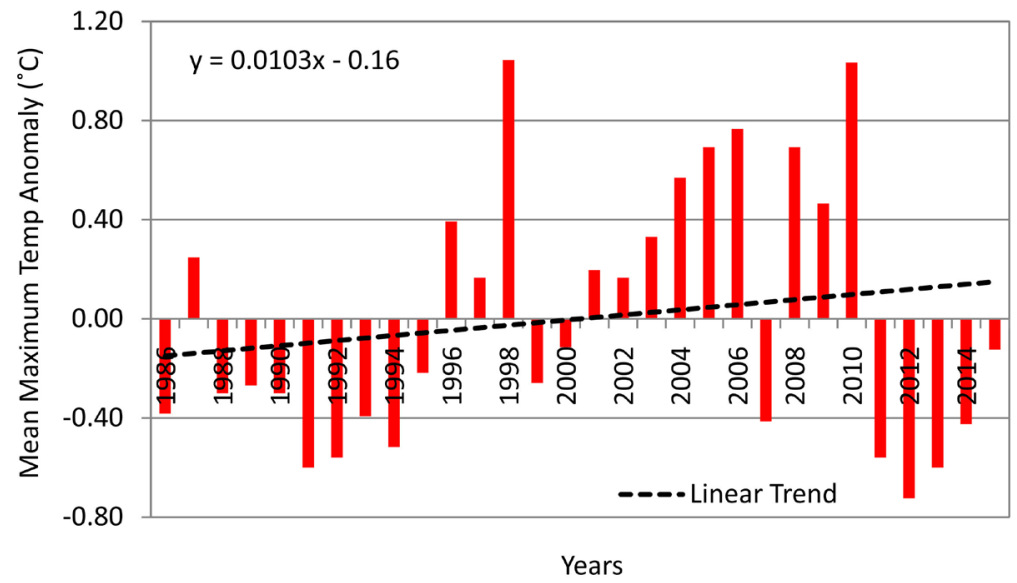

Figure 7. Mean maximum temperature anomaly for Owerri using jackknife method to compute the base data: Owerri 1985-2017. Source: Stanley I Echebima, Benjamin C. Ndukwu \& Andrew A. Obafemi. 
Table 1. Comparison of results for Owerri using the simple mean, median and Jackknife methods for Base computation for mean minimum temperature.

\begin{tabular}{cccc}
\hline Analysis Method & Mean Method & Median Method & Jackknife Method \\
\hline Linear Trend & $y=0.0186 x-0.287$ & $y=0.0186 x-0.297$ & $y=0.0193 x-0.2989$
\end{tabular}

Source: Stanley I Echebima, Benjamin C. Ndukwu \& Andrew A. Obafemi.

Table 2. Comparison of results for mean, median and Jackknife methods of anomaly computation for mean maximum temperature.

\begin{tabular}{cccc}
\hline Analysis Method & Simple Mean Method & Median Method & Jackknife Method \\
\hline Linear Trend & $\mathrm{y}=0.01 \mathrm{x}-0.1543$ & $\mathrm{y}=0.01 \mathrm{x}+0.0107$ & $\mathrm{y}=0.0103 \mathrm{x}-0.16$ \\
\hline
\end{tabular}

Source: Stanley I Echebima, Benjamin C. Ndukwu \& Andrew A. Obafemi.

Table 3. (a) Mean min temp anomalies; (b) Mean max temp anomalies.

(a)

\begin{tabular}{|c|c|c|c|}
\hline Year & Simple Mean & Median Method & Jackknife Method \\
\hline 1986 & -0.76 & -0.77 & -0.79 \\
\hline 1987 & 0.27 & 0.26 & 0.28 \\
\hline 1988 & -0.12 & -0.13 & -0.13 \\
\hline 1989 & -0.55 & -0.56 & -0.57 \\
\hline 1990 & 0.01 & 0 & 0.01 \\
\hline 1991 & -0.11 & -0.12 & -0.12 \\
\hline 1992 & -0.29 & -0.3 & -0.3 \\
\hline 1993 & -0.41 & -0.42 & -0.43 \\
\hline 1994 & -0.58 & -0.59 & -0.6 \\
\hline 1995 & -0.76 & -0.77 & -0.79 \\
\hline 1996 & 0.03 & 0.02 & 0.03 \\
\hline 1997 & -0.12 & -0.13 & -0.13 \\
\hline 1998 & 0.56 & 0.55 & 0.58 \\
\hline 1999 & -0.02 & -0.03 & -0.02 \\
\hline 2000 & 0.23 & 0.22 & 0.24 \\
\hline 2001 & 0.25 & 0.24 & 0.26 \\
\hline 2002 & 0.16 & 0.15 & 0.16 \\
\hline 2003 & 0.36 & 0.35 & 0.37 \\
\hline 2004 & 0.01 & 0 & 0.01 \\
\hline 2005 & 0.35 & 0.34 & 0.36 \\
\hline 2006 & 0.35 & 0.34 & 0.36 \\
\hline 2007 & -0.13 & -0.14 & -0.14 \\
\hline 2008 & 0.3 & 0.29 & 0.31 \\
\hline 2009 & 0.5 & 0.49 & 0.52 \\
\hline 2010 & 0.96 & 0.95 & 0.99 \\
\hline 2011 & 0.13 & 0.12 & 0.13 \\
\hline 2012 & -0.15 & -0.16 & -0.16 \\
\hline 2013 & 0.05 & 0.04 & 0.05 \\
\hline 2014 & -0.3 & -0.31 & -0.31 \\
\hline 2015 & -0.16 & -0.17 & -0.17 \\
\hline
\end{tabular}


(b)

\begin{tabular}{|c|c|c|c|}
\hline Year & Mean Method & Median Method & Jackknife Method \\
\hline 1 & -0.37 & -0.20 & -0.38 \\
\hline 2 & 0.24 & 0.41 & 0.25 \\
\hline 3 & -0.29 & -0.13 & -0.30 \\
\hline 4 & -0.26 & -0.09 & -0.27 \\
\hline 5 & -0.29 & -0.13 & -0.30 \\
\hline 6 & -0.58 & -0.41 & -0.60 \\
\hline 7 & -0.54 & -0.38 & -0.56 \\
\hline 8 & -0.38 & -0.22 & -0.39 \\
\hline 9 & -0.50 & -0.33 & -0.52 \\
\hline 10 & -0.21 & -0.04 & -0.22 \\
\hline 11 & 0.38 & 0.55 & -0.39 \\
\hline 12 & 0.16 & 0.33 & 0.17 \\
\hline 13 & 1.01 & 1.18 & 1.04 \\
\hline 14 & -0.25 & -0.08 & -0.26 \\
\hline 15 & -0.11 & 0.05 & -0.11 \\
\hline 16 & 0.19 & 0.36 & 0.2 \\
\hline 17 & 0.16 & 0.33 & 0.17 \\
\hline 18 & 0.32 & 0.48 & 0.33 \\
\hline 19 & 0.55 & 0.72 & 0.57 \\
\hline 20 & 0.67 & 0.84 & 0.69 \\
\hline 21 & 0.74 & 0.91 & 0.77 \\
\hline 22 & -0.4 & -0.23 & -0.41 \\
\hline 23 & 0.67 & 0.84 & 0.69 \\
\hline 24 & 0.45 & 0.62 & 0.47 \\
\hline 25 & 1 & 1.17 & 1.03 \\
\hline 26 & -0.54 & -0.38 & -0.56 \\
\hline 27 & -0.7 & -0.53 & -0.72 \\
\hline 28 & -0.58 & -0.41 & -0.6 \\
\hline 29 & -0.41 & -0.24 & -0.42 \\
\hline 30 & -0.12 & 0.05 & -0.12 \\
\hline
\end{tabular}

like Owerri with no spikes or dipoles in the data like winter and summer variations, there should be no significant difference in the methods used to compute the anomalies.

Starting with a prior $95 \%$ confidence and using one way ANOVA the results is shown in Table 4 and Table 5 below for mean minimum temperature and mean maximum temperature respectively. 
Table 4. ANOVA result for mean minimum temperature anomalies.

\begin{tabular}{|c|c|c|c|c|c|c|}
\hline \multicolumn{7}{|l|}{ ANOVA: Single Factor } \\
\hline \multicolumn{7}{|c|}{ SUMMARY: Mean Minimum Temperature Anomaly } \\
\hline Groups & Count & Sum & Average & Variance & & \\
\hline Mean Method & 30 & 0.06 & 0.002 & 0.1526441 & & \\
\hline Median Method & 30 & -0.24 & -0.008 & 0.1526441 & & \\
\hline Jackknife Method & 30 & $-3.05 \mathrm{E}-16$ & $-1.018 \mathrm{E}-17$ & 0.1639862 & & \\
\hline \multicolumn{7}{|l|}{ ANOVA } \\
\hline Source of Variation & SS & df & MS & $\mathrm{F}$ & P-value & F crit \\
\hline Between Groups & 0.00168 & 2 & 0.00084 & 0.00537 & 0.994645 & 3.101296 \\
\hline Within Groups & 13.609 & 87 & 0.15642483 & & & \\
\hline Total & 13.6106 & 89 & & & & \\
\hline
\end{tabular}

Source: Stanley I Echebima, Benjamin C. Ndukwu \& Andrew A. Obafemi.

Table 5. ANOVA result for mean maximum temperature anomalies.

\begin{tabular}{|c|c|c|c|c|c|c|}
\hline \multicolumn{7}{|l|}{ ANOVA: Single Factor } \\
\hline \multicolumn{7}{|c|}{ SUMMARY: Mean Maximum Temperature Anomaly } \\
\hline Groups & Count & Sum & Average & Variance & & \\
\hline Mean Method & 30 & 0.01 & 0.00033333 & 0.2529826 & & \\
\hline Median Method & 30 & 5.04 & 0.168 & 0.2542648 & & \\
\hline Jackknife Method & 30 & -0.75 & -0.025 & 0.2692534 & & \\
\hline \multicolumn{7}{|l|}{ ANOVA } \\
\hline Source of Variation & SS & $\mathrm{df}$ & MS & $\mathrm{F}$ & P-value & F crit \\
\hline Between Groups & 0.66003 & 2 & 0.33001444 & 1.275006 & 0.284598 & 3.101296 \\
\hline Within Groups & 22.5185 & 87 & 0.25883364 & & & \\
\hline Total & 23.1786 & 89 & & & & \\
\hline
\end{tabular}

Source: Stanley I Echebima, Benjamin C. Ndukwu \& Andrew A. Obafemi.

The ANOVA result shows that the critical value of $\mathrm{P}$ is greater than 0.05 which suggests non significance implying that we accept the null hypothesis. Further to that, is that the calculated F value of 0.00537 is less than the tabulated $\mathrm{F}$ value (=F critical) of 3.101296 meaning that there is no significant difference in the mean of the methods of computing the anomalies.

Therefore using the simple mean suffices in analyzing weather data in Owerri since the median and Jackknife methods are computationally intensive and do not exhibit major difference in the outcome.

The ANOVA result shows that the critical value of $\mathrm{P}(0.284598)$ is greater than 0.05 which suggests non significance implying that we accept the null hy- 
pothesis. Further to that is that the calculated $\mathrm{F}$ value of 1.275006 is less than the tabulated $\mathrm{F}$ value (=F critical) of 3.101296 meaning that there is no significant difference in the mean of the methods of computing the anomalies.

It can be stated therefore, that regardless of the method of anomaly computation therefore, it is obvious that night and day time temperatures has increased in Owerri and environ. Using the result of the simple mean in Figure 2 and Figure 5 however, indicate that night time is warming up by about $0.0186^{\circ} \mathrm{C}$ per year and day time is warming up by about $0.01^{\circ} \mathrm{C}$ per year, though all rates are not at steady or uniform rates.

\section{Rainfall}

The result for the rainfall study of Owerri is presented in the plots shown in Figures 8-10 below respectively for the case where the climate average is calculated using the simple mean, median and jackknife methods, before standardizing the anomalies.

Rainfall showed a decrease in the rate, with the mean and jackknife methods returning same results, implying that it are easier and better to use the mean method to compute the climatic base factor. One of the reasons for the decrease in rainfall could be reduced evapotranspiration due to vegetal loss.

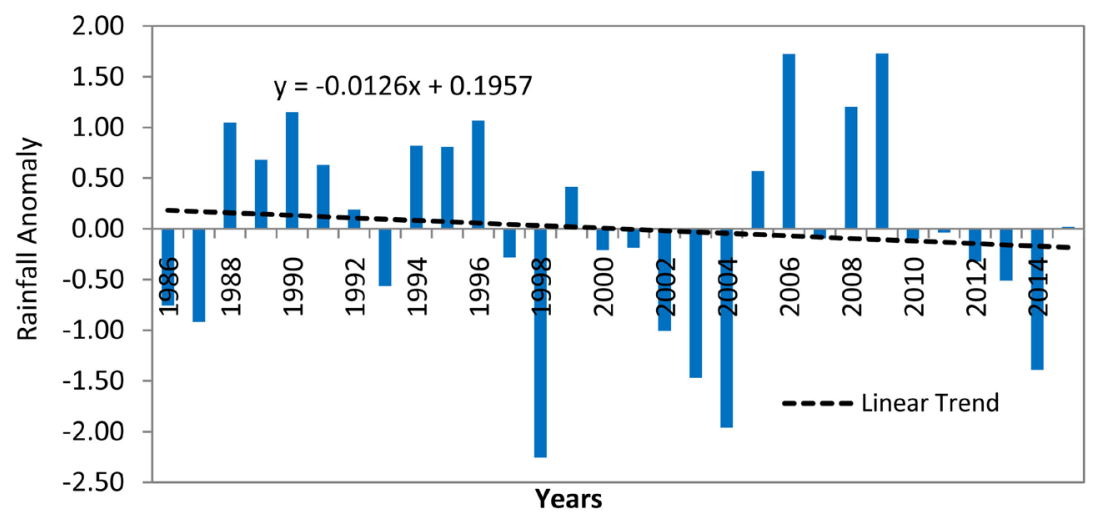

Figure 8. Standardized rainfall anomaly for Owerri computing the base by mean method. Source: Stanley I Echebima, Benjamin C. Ndukwu \& Andrew A. Obafemi.

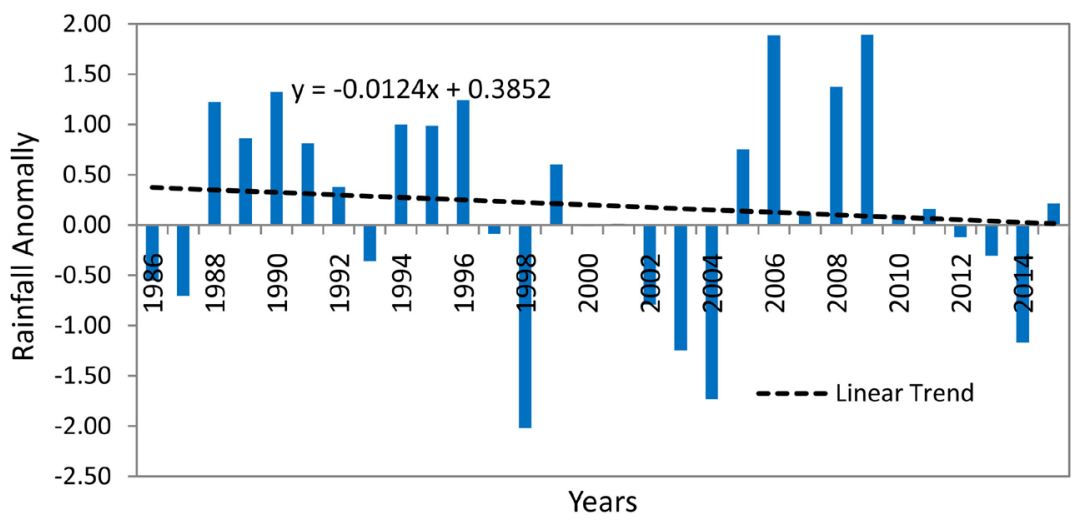

Figure 9. Standardized rainfall anomaly for Owerri computing the base by median method. Source: Stanley I Echebima, Benjamin C. Ndukwu \& Andrew A. Obafemi. 


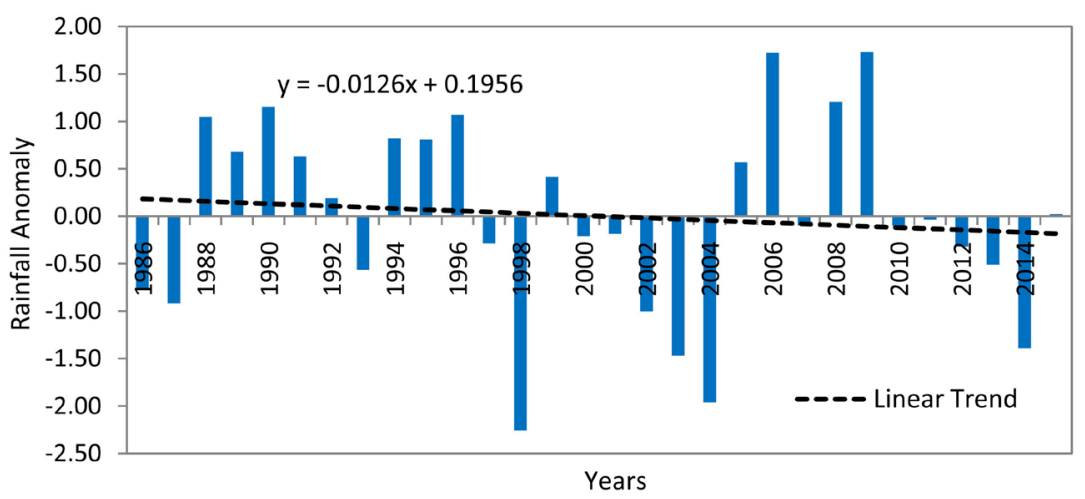

Figure 10. Standardized rainfall anomaly for Owerri using jackknife method to compute the base factor. Source: Stanley I Echebima, Benjamin C. Ndukwu \& Andrew A. Obafemi.

\section{Conclusions}

Starting with a $95 \%$ confidence in a null hypothesis, the analysis of variance shows that there are no significant differences in the results obtained in the anomaly time series using either of the mean, median, or jackknife methods to compute the base factor.

Therefore, the simple mean method of computing the base factor is sufficient during the process of anomaly computation and analysis for Owerri climate data, since the method is simple and does not involve heavy computation like the median and jackknife methods.

Using linear regression method to interpret the plot of the anomalies shows that a warming climate change has taken place in Owerri in that the daytime and nighttime temperatures have increased within the period from 1986 to 2015 while rainfall showed a decrease in the same period.

The trend shows that nighttime and daytime are getting warmer by $0.0186^{\circ} \mathrm{C}$ per year and $0.01^{\circ} \mathrm{C}$ per year respectively, though with fluctuation while rainfall decreases at a rate of 0.0126 per year, though not at a uniform rates, but with fluctuations.

At the time of publishing, the year of relocating the meteorological synoptic station from the Owerri urban to the premises of the Imo Airport, about $25 \mathrm{~km}$ away was not known and the composite method in base factor computation could not be tested.

\section{Recommendations}

With a warming climate change that has taken place in Owerri and environ, adaptation measures like tree planting (amongst others) should be undertaken by the state government and residents of area in order to reduce its impacts.

The simple mean method is recommended for the computation of the climate averages (base factor) due to its simplicity of use and also the fact that there is no significant difference in the result obtained when compared with the median or jackknife methods.

The government of the state should also embark on spatial planning, urban 
review and controls with emphasis on "greening" and sustainable use of natural resources in order to safeguard the environment and local climate.

\section{Conflicts of Interest}

The authors declare no conflicts of interest regarding the publication of this paper.

\section{References}

[1] WMO (2017) Normals Guide to Climate. http://www.wmo.int/pages/prog/wcp/ccl/guide/documents/Normals-Guide-to-Cli mate-190116_en.pdf

[2] Kelly, D. and Fretwell, M. (2012) Complete Geography for IGCSE. 201.

[3] Kawale, J., Chatterjee, S., Kumar, A., Liess, S., Steinbach, M. and Kumar, V. (2011) Anomaly Construction in Climate Data: Issues and Challenges. Conference on Intelligent Data Understanding, Mountain View, 19-21 October 2011, 1-15.

[4] IRI International Research Institute for Climate and Society, Columbia University (2017) http://iridl.Ideo.columbia.edu/dochelp/StatTutorial/Climatologies/index.html

[5] Beck, H.E., Zimmermann, N.E., McVicar, T.R., Vergopolan, N., Berg, A. and Wood, E.F. (2018) Present and Future Koopen-Geiger Climate Classification Maps at 1-km Resolution. Scientific Data, 5, Article No. 180214.

https://doi.org/10.1038/sdata.2018.214

[6] NIMET (2016) Nigeria Climate Review Bulletin. 8-11.

[7] Ukaegbu, K.O.E., Iwuji, M.C., Uche, C.C., Osumgborogwu, I.E. and Amangbara, G.T. (2017) Spatial Assessment of Temperature and Land Cover Change as Climate Change Monitoring Strategies in Owerri, Nigeria. Journal of Geography, Environment and Earth science International, 11, 1-9.

[8] Selemo, A.O.I., Ananaba, S.E., Nwagbara, J.O., Egejuru, V.E. and Nwugha, V. (2011) Geospatial Analysis of Rainfall Temperature and Evaporation Data of Owerri for Ten Years. Journal of Atmospheric and Climate Science, 2, 196-205. https://doi.org/10.4236/acs.2012.22020

[9] Wu, C. (1986) Jackknife Bootstrap and Other Re-Sampling Methods in Regression Analysis. The Annals of Statistics, 14, 1261-1295.

https://doi.org/10.1214/aos/1176350142 